\title{
Evaluation of Patient's Knowledge, Attitude, and Practice of Cross-Infection Control in Dentistry during COVID-19 Pandemic
}

\author{
Muhammad Adeel Ahmed ${ }^{1} \quad$ Rizwan Jouhar $^{1} \quad$ Samira Adnan $^{2} \quad$ Naseer Ahmed $^{3,4} \quad$ Tuba Ghazal ${ }^{5}$ \\ Necdet Adanir ${ }^{1}$
}
${ }^{1}$ Department of Restorative Dentistry, College of Dentistry, King Faisal University, Al Ahsa, Saudi Arabia
${ }^{2}$ Department of Operative Dentistry, Sindh Institute of Oral Health Sciences, Jinnah Sindh Medical University, Karachi, Pakistan
${ }^{3}$ Department of Prosthodontics, Altamash Institute of Dental Medicine, Karachi, Pakistan
${ }^{4}$ Prosthodontics Unit, University Sains Malaysia,
School of Dental Sciences, Kubang Kerian, Kelantan
${ }^{5}$ Department of Community Dentistry, Dr. Ishrat-ul-ebad khan Institute of Oral Health Science, Dow University of Health
Sciences, Karachi, Pakistan

\author{
Address for correspondence Muhammad Adeel Ahmed, BDS, MFDS \\ RCSEd (UK), FCPS, Department of Restorative Dentistry, College \\ of Dentistry, King Faisal University, Al Ahsa 31982, Saudi Arabia \\ (e-mail: mshakeel@kfu.edu.sa).
}

Eur J Dent:2020;14(suppl S1):S1-S6

\begin{abstract}
Objectives The aim of this study was to evaluate the patient's knowledge, attitude, and practice of cross-infection control in dentistry during coronavirus diseases 2019 (COVID-19).

Materials and Methods This cross-sectional observational study was conducted at Altamash Institute of Dental Medicine, Karachi from June 2020 to August 2020. A total of 775 patients participated to fill the 20 item questionnaire. After scrutiny, 25 questionnaire forms were excluded due to incomplete information. The Questionnaire was divided in to four sections. First section obtained patients sociodemographic information, while knowledge of patients regarding cross-infection control during COVID-19 pandemic was evaluated in second section. The purpose of third section was to assess attitude and fourth section was designed to evaluate practice. Likert's 3 -point scale was used for registration of participant's response. The reliability of questionnaire was assessed through Crohnbach's $\alpha(\alpha=0.74)$. Statistical analysis was performed after entering data in SPSS version 25 . Independent $t$-test was used to evaluate the difference in patients' knowledge, attitude, and practice. A $p$-value of $\leq 0.05$ was considered as statistically significant.

Keywords

- COVID-19

- cross-infection control

- knowledge, attitude, and practice

Results Majority of the participants agreed that COVID-19 is a highly contagious disease $(631,97 \%)$ and daily screening of staff, dental assistants, dentists, and patients is necessary $(568,75.7 \%)$ along with proper sterilization of instruments and disinfection of dental operatory $(650,86.66 \%)$. A large number of participants also agreed that proper disposal of waste is utmost important for cross-infection control
\end{abstract}

DoI https://doi.org/ 10.1055/s-0040-1721295 ISSN 1305-7456. (c) 2020. European Journal of Dentistry.

This is an open access article published by Thieme under the terms of the Creative Commons Attribution-NonDerivative-NonCommercial-License, permitting copying and reproduction so long as the original work is given appropriate credit. Contents may not be used for commercial purposes, or adapted, remixed, transformed or built upon. (https://creativecommons.org/licenses/by-nc-nd/4.0/)

Thieme Medical and Scientific Publishers Pvt. Ltd., A-12, 2nd Floor, Sector 2, Noida-201301 UP, India 
(601, 80.24\%) and patient waiting area should also be marked with social distancing sign $(620,82.66 \%)$. However, when asked about the common route of COVID-19 transmission in dentistry, 341 (45.5\%) participants were of the opinion that it is not through aerosol (water droplets) generated during dental procedures.

Conclusions Dental health professionals should take additional measures to educate dental patients on mechanism of potential spread of COVID-19 through the aerosols and droplets generated during dental procedures. They should also encourage the dental patients to be vigilant and question the cross-infection control measures practiced by the dentist to whom they go for dental treatment, in order to decrease their chances of acquiring an infection during their visit to the dental office.

\section{Introduction}

Cross-infection control has always held a prime importance in dentistry. ${ }^{1}$ It is considered uncompromisable not only for patient safety but also for dentist and their staff. ${ }^{2,3}$ Cross-infection transmission occurs during dental treatment involving blood, saliva, and procedures generating aerosols. ${ }^{4}$ These aerosols remain suspended in air for an extended time and could possibly be a substantial source of infection in case of treating infected patient. ${ }^{5}$ Several diseases remain silent for considerable time before showing symptoms. ${ }^{6}$ Cross-infection in dental practice can spread by organisms such as hepatitis B virus, mycobacterium tuberculosis, herpes simplex virus 1 and 2, hepatitis $C$ virus, mumps, rubella, influenza, cytomegalovirus, and human immunodeficiency virus/acquired immunodeficiency syndrome. Additionally, many communicable diseases have been part of global emergence and re-emergence. ${ }^{7}$

Currently, emergence of coronavirus disease 2019 (COVID-19) significantly affected the mass population globally. ${ }^{8}$ COVID-19 is a highly contagious disease ${ }^{9}$ and has spread to 212 countries around the world within short span of time (source: WHO situation report-204). In the beginning of this year most dental services were closed or restricted to emergency treatment only because of lack of proper guidelines for COVID-19 infection control along with fear and anxiety among dental practitioners. ${ }^{10}$ With the passage of time, people have realized that they have to live with coronavirus disease until COVID-19 vaccine is available; therefore, life is resuming to normal with certain modification such as social distancing, wearing face mask, avoiding gatherings, and hand hygiene through frequent washing or sanitization. ${ }^{11}$

In light of current COVID-19 pandemic, American Dental Association (ADA) and Centers for Disease Control and Prevention (CDC) guidelines for cross-infection control have changed (source: ADA Coronavirus (COVID-19) Center for Dentists). Dentists around the world are obliged to implement modified infection control protocols. Moreover, it is also true that understanding of patients regarding COVID-19 transmission is also enhanced due to influx of information through social media.
Since scant literature is available in this regard, it is worthwhile to evaluate the patient's knowledge, attitude, and practice of cross-infection control in dentistry during COVID-19. ${ }^{12-14}$ Assessment of patient's knowledge, attitude, and practice will help us to identify loopholes in dental practices and encourage dental practitioners to improve implementation of cross-infection control protocols. Knowing patient's perspective will tacitly aid in gaining their confidence for dental treatment during COVID-19 pandemic.

\section{Materials and Methods}

This cross-sectional observational study was conducted at Altamash Institute of Dental Medicine, Karachi, from June 2020 to August 2020, after obtaining ethical approval (AIDM/EC/08/2020/04). Sample size was calculated using Open Epi, considering knowledge level ${ }^{15}$ of $72.58 \pm 2.189$ with the power of study 80 and keeping confidence interval of 0.95 with $\alpha$ error of $0.05 \%$, the total estimated sample size was 640 participants, which was then overestimated to cover maximum responses to 775 subjects. All patients of either gender and aged 20 between 75 years coming for routine dental check-ups and consenting to be part of the study were included using nonprobability convenience sampling. Likert's 3-point scale was used for registration of participant's response. The reliability of questionnaire was assessed through Crohnbach's $\alpha$ $(\alpha=0.74)$.

A total of 775 patients participated to fill the questionnaire. After scrutiny, 25 questionnaire forms were excluded due to incomplete information. Questionnaire was divided in to four sections. In the first section, patient sociodemographic information was obtained. Second section consisted of eight closed ended questions, which were designed to assess patient's knowledge regarding cross-infection control during COVID-19 pandemic in dentistry. These included knowledge about common route of COVID-19 transmission in dentistry, daily health screening and body temperature measurement for every patient and working dental staff, personal protective equipment (PPE) for dentist, sterilization and disinfection of dental operatory, control of aerosol 
spread by measures such as cross-ventilation or extra-oral dental suction, and proper disposal of dental waste.

The third section of questionnaire had seven closed ended questions, which were designed to evaluate patient attitude. These questions comprised of daily update of COVID-19 record for dental staff and patients, social distancing sign in patient's waiting area, hand sanitization of every patient followed by wearing gloves, disposal of PPE after every patient, sterilization monitoring, and disinfection of dental operatory after every patient. Finally, the purpose of last section was to assess dental practice by asking closed ended questions about dental staff and patient screening method, sterilization and disinfection protocol, management of patient's appointment to avoid crowding, and waste disposal protocols.

\section{Statistical Analysis}

Statistical analysis was performed after entering data in SPSS version 25. Descriptive statistics were used to obtain frequency, percentage of independent, and dependent variables. Independent $t$-test was used to evaluate the difference in patients' knowledge, attitude, and practice with gender and education status, while spearman correlation was used to identify any relationship between knowledge and practice levels of participants. A $p$-value of $\leq 0.05$ was considered as statistically significant.

\section{Results}

In this cross-sectional observational study, the recorded response rate was $90.79 \%$. The internal consistency of items in well-structured questionnaire obtained through Crohnbach's $\alpha$ was $(\alpha=0.74)$. In our study, majority of participants were females $(381,50.8 \%)$ from a common age bracket of 20 to 30 years $(405,54 \%)$. More than two-third of participants were graduates, while financially most of subjects $(478,63.7 \%)$ opted that their income was in less than enough category during the pandemic as presented in $\boldsymbol{-}$ Table $\mathbf{1}$.

Table 1 Demographic information of participants $(n=750)$

\begin{tabular}{|l|l|l|}
\hline Demographics & Variables & $\mathbf{n ( \% )}$ \\
\hline \multirow{4}{*}{ Gender } & Male & $369(49.2)$ \\
\cline { 2 - 3 } & Female & $381(50.8)$ \\
\hline \multirow{5}{*}{ Education status } & $20-30 \mathrm{y}$ & $405(54.0)$ \\
\cline { 2 - 3 } & $31-40 \mathrm{y}$ & $93(12.4)$ \\
\cline { 2 - 3 } & $51-60 \mathrm{y}$ & $158(21.1)$ \\
\cline { 2 - 3 } & Above 60 y & $94(12.5)$ \\
\cline { 2 - 3 } & Pregraduation & $65(8.7)$ \\
\cline { 2 - 3 } Income & Graduation & $558(74.4)$ \\
\cline { 2 - 3 } & Postgraduation & $127(16.9)$ \\
\hline & Less than enough & $478(63.7)$ \\
\cline { 2 - 3 } & Enough & $187(24.9)$ \\
\cline { 2 - 3 } & Enough and exceed & $85(11.3)$ \\
\hline
\end{tabular}

In our study, majority of participants $(631,97 \%)$ agreed that COVID-19 is a highly contagious disease and (568, 75.7\%) participants opted for routine screening of auxiliary staff, dentists, and patients. Five-hundred sixty-four (75.2\%) participants agreed that body temperature and health screening are the first step of identifying suspected individual and 650 (86.66\%) participants believed that sterilization of instruments and disinfection of dental operatory is mandatory. However, 592 (78.9\%) participants agreed that extra-oral suction or cross-ventilation can control aerosol (water droplets) spread. Four-hundred fifty (60\%) participants recognized that hand gloves, face mask, and protective clothing are necessary for dentist and patient protection.

Additionally, $601 \quad(80.24 \%)$ participants believed that proper disposal of waste is utmost important for cross-infection control. Likewise, 583 (89\%) participants agreed the dentists should keep and update record of daily staff and patient screening for COVID-19. A total of 556 (74.13\%) participants were of the opinion that dentist and dental assistant should discard worn facemask, gloves, and protective clothing after every patient, while 499 (76\%) participants opted that high-volume suction is necessary practice for every patient. Additionally, 702 (93.6\%) participants agreed that dental chair and accessories should be disinfected after every patient. Also, 661 (88.1\%) participants agreed that the dentist should regularly monitor the performance of sterilizer and 620 (82.66\%) respondents emphasized that patient waiting area should be marked with social distancing sign. Furthermore, 468 (62.4\%) participants recognized that the dentist should be asked, how they are screening dental staff and patients for COVID-19, while 450 (60\%) respondents believed that the dentist should be asked about sterilization protocols. Five hundred fifteen (68.63\%) participants reinforced that dentist should be asked about the disinfection of dental operatory and 557 (74.26\%) participants considered that the dentist should be asked about management of patient appointments to avoid crowding. Nevertheless, when asked about the common route of COVID-19 transmission in dentistry, 341 (45.5\%) participants were of the opinion that it is not through aerosol (water droplets) generated during dental procedures as described in - Table 2 .

In this study, there was a significant difference $(p=0.000)$ among the knowledge, attitude, and practice levels in both male and females when analyzed through independent $t$-test keeping the level of significance at $(p \leq 0.05)$. Lastly, there was a significant difference between education status and knowledge, practices, and attitude levels of participants. Moreover, a significant relation $(p=0.001)$ was also found between knowledge and practice levels of participants in the current study.

\section{Discussion}

A significant number of studies have been conducted recently to assess the knowledge, practices, and attitude of dental health care providers regarding the coronavirus disease or COVID-19 in the wake of the current pandemic that has affected the entire globe. ${ }^{10,13,16}$ Although the community of 
Table 2 Characteristics of knowledge and attitude and practice of patients about COVID-19 $(n=750)$

\begin{tabular}{|c|c|c|c|}
\hline Question & Agree, $n(\%)$ & Disagree, $n(\%)$ & Neutral, $n(\%)$ \\
\hline COVID-19 is highly contagious disease & $631(97)$ & $158(21.1)$ & $96(12.8)$ \\
\hline $\begin{array}{l}\text { Common route of COVID-19 transmission in } \\
\text { dentistry is through aerosol (water droplets) } \\
\text { generated during dental procedures }\end{array}$ & $316(42.1)$ & $341(45.5)$ & $93(12.4)$ \\
\hline $\begin{array}{l}\text { Daily screening of staff, dental assistants, } \\
\text { dentists, and patients is necessary }\end{array}$ & $568(75.7)$ & $93(12.4)$ & 89 (11.9) \\
\hline $\begin{array}{l}\text { Body temperature and health screening is the } \\
\text { first step of identifying suspected individual }\end{array}$ & $564(75.2)$ & $93(12.4)$ & $93(12.4)$ \\
\hline $\begin{array}{l}\text { Sterilization of instruments and disinfection of } \\
\text { dental operatory is mandatory }\end{array}$ & $650(86.66)$ & $30(4)$ & $70(9.33)$ \\
\hline $\begin{array}{l}\text { Extra-oral suction or cross ventilation could } \\
\text { control aerosol (water droplets) spread }\end{array}$ & $592(78.9)$ & $65(8.7)$ & $93(12.4)$ \\
\hline $\begin{array}{l}\text { Hand gloves. face mask, and protective clothing } \\
\text { are necessary for dentist }\end{array}$ & $450(60)$ & $98(13.06)$ & $202(26.93)$ \\
\hline $\begin{array}{l}\text { Proper disposal of waste is utmost important } \\
\text { for cross-infection control }\end{array}$ & $601(80.24)$ & $89(11.9)$ & $60(8)$ \\
\hline $\begin{array}{l}\text { Dentists should keep and update record of daily } \\
\text { staff and patient screening for COVID-19 }\end{array}$ & $583(89)$ & $58(9)$ & $9(2)$ \\
\hline $\begin{array}{l}\text { Dentist and dental assistant should discard } \\
\text { worn facemask, gloves, and protective clothing } \\
\text { after every patient }\end{array}$ & $556(74.13)$ & $154(20.5)$ & $40(5.33)$ \\
\hline $\begin{array}{l}\text { High volume suction should be used in dental } \\
\text { practice for every patient }\end{array}$ & $499(76)$ & $143(22)$ & $8(2)$ \\
\hline $\begin{array}{l}\text { Dental surgery should have extra-oral dental } \\
\text { suction or cross ventilation to control aerosol } \\
\text { (water droplets) spread }\end{array}$ & $580(77.33)$ & $93(12.4)$ & $77(10.26)$ \\
\hline $\begin{array}{l}\text { Dental chair and accessories should be } \\
\text { disinfected after every patient }\end{array}$ & $702(93.6)$ & $40(5.33)$ & $8(1.06)$ \\
\hline $\begin{array}{l}\text { Dentist should regularly monitor the } \\
\text { performance of sterilizer }\end{array}$ & $661(88.1)$ & $80(10.66)$ & $9(1.2)$ \\
\hline $\begin{array}{l}\text { Patient's waiting area should be marked with } \\
\text { social distancing sign }\end{array}$ & $620(82.66)$ & $80(10.66)$ & $50(6.66)$ \\
\hline $\begin{array}{l}\text { The dentist should be asked, how they } \\
\text { are screening dental staff and patients for } \\
\text { COVID-19 }\end{array}$ & $468(62.4)$ & $182(24.3)$ & $100(13.33)$ \\
\hline $\begin{array}{l}\text { The dentist should be asked about sterilization } \\
\text { protocols }\end{array}$ & $450(60)$ & $58(7.73)$ & $242(32.26)$ \\
\hline $\begin{array}{l}\text { The dentist should be asked about the } \\
\text { disinfection of dental operatory }\end{array}$ & $515(68.63)$ & $25(3.33)$ & $210(28)$ \\
\hline $\begin{array}{l}\text { The dentist should be asked about the } \\
\text { management of patient appointments to avoid } \\
\text { crowding }\end{array}$ & $557(74.26)$ & $100(13.33)$ & $93(12.4)$ \\
\hline $\begin{array}{l}\text { The dentist should be asked about the waste } \\
\text { disposal protocols }\end{array}$ & $657(87.6)$ & $45(6)$ & $48(6.4)$ \\
\hline
\end{tabular}

Abbreviation: COVID-19, coronavirus disease 2019.

dental professionals is considered as one of the health professionals at highest risk of getting infected, ${ }^{17}$ the concerns and comprehension of dental patients relevant to the ongoing pandemic have yet to be evaluated. Studies have been conducted previously on the knowledge and attitude of dental patients regarding other infections that similarly spread through aerosols, macrodroplets, and sharing of equipment, ${ }^{18}$ including severe acute respiratory syndrome ${ }^{19}$ and Middle East respiratory syndrome..$^{20}$ These studies found that patients were aware of how these infections spread, and they had significant concerns regarding undergoing dental treatment because of the fear of getting infected. If dental practices are expected to continue providing quality dental services to their patients, it is essential that the understanding of patients regarding the means of spread of coronavirus disease should also be assessed. This includes their vigilance in observing and ensuring the safety and infection control practices followed by any dental health care provider they visit. It is important to make certain that they have minimal chances of exposure to COVID-19 infection during dental visit. These measures 
should include relatively simple steps that are to be followed by dental health care providers such as screening of dental patients and staff by checking body temperature using a noncontact forehead thermometer, ${ }^{21}$ as recommended by health care authorities. Currently, body temperature is being used worldwide as an important initial parameter to determine if a person may potentially be with infected with COVID-19. Any patient or staff member exhibiting temperature higher than $100.4^{\circ} \mathrm{F}$ or $38^{\circ} \mathrm{C}$ should be advised to get quarantined and report to the local health care authorities. Screening can also be done by taking appropriate history and asking questions regarding any relevant symptoms that the patient or the dental staff might have that could be suspected of COVID-19, as well as history of traveling from any area where they may have potentially got infected. ${ }^{21,22}$ These noninvasive measures could help to identify suspect individuals, after which they could be directed to take relevant measures as recommended by local health care authorities. This would help limit the infection to other members of the community. Our study shows that the dental patients are aware that these measures should be in place at the dental clinics, which is a positive aspect regarding their current knowledge relevant to COVID-19.

The responses of most of patients regarding the routine use of various sterilization techniques and methods to prevent cross-infection control demonstrated that the majority of patients are well aware of benefits of using these protocols to prevent cross-infection in the dental office. Even though these practices should be in place as part of the universal protocol for cross-infection control, in the current situation they become even more pertinent. With the highly contagious nature of the coronavirus, and the evolving evidence regarding the mechanism of spread and cross-infection, it is essential that measures that have shown effectiveness to control the spread of other infections be at least prudently followed. These include the use of high volume suction to control the spread of aerosols. ${ }^{21}$ The necessity of using PPE, proper sterilization of instruments, disinfection of the operatory after every patient, and proper disposal of wastes are part of the universal precautions that should already be in place in every dental office, to prevent the spread of not only COVID-19 but other infectious diseases as well. ${ }^{22}$ The positive response of the dental patients showed that they are aware of the importance of all these measures for cross-infection control as well.

Because of the continuous coverage of this pandemic by both electronic and social media, majority of people around the world are by now quite familiar with the nature of this widely spreading disease. The same was observed in our study, where the majority of people were aware of the infectious nature of the COVID-19. A study related to the knowledge and attitudes of parents of pediatric dental patients to the COVID-19 pandemic showed that $91.8 \%$ of the parents believed that their children could get infected with the coronavirus during dental treatment. ${ }^{23}$ The majority of parents in the same study also correctly identified aerosol and droplet in the dental operatory, as a potential source for this spread. However, in our study we found dissimilar results. It seems that a large number of dental patients who were respondents in this study did not realize that it is actually the aerosol which is generated during the majority of dental procedures that may be the cause of spread of coronavirus in the dental setting. This fact may be overlooked by the patients as they may not necessarily note the aerosol that is generated during a dental procedure, even though they may be aware that coronavirus spreads through droplets. ${ }^{19}$ The dental community could highlight this fact so that the route of spread of this infection in dental offices becomes clear to the dental patients. This would also help the dental patients understand better when, as per the current recommendations, a dental procedure which generates relatively lower amount of aerosol is offered to them instead of an alternative procedure just to prevent the generation of aerosol and ultimately decrease the chance of infection by COVID-19. ${ }^{24}$ In addition, any data regarding the actually acquiring COVID-19 as a result of dental treatments is yet to emerge.

It was encouraging to note that the patients found it appropriate to inquire from the dental health professionals regarding their cross-infection control practices. This elucidates that dental patients are conscious regarding the potential for getting infected with certain diseases including the coronavirus through inappropriate cross-infection control during dental procedures. In the current scenario involving the outbreak of a potentially fatal coronavirus globally, the majority of the patients are aware of the necessity of screening to identify individuals who may be infected and could become the source of infection for other people. It would be prudent of dental patients to make sure that their dental health practitioner is also aware of such precautions and is implementing them practically in their dental office. Since this infection is airborne and has been found to be transmitted through aerosol, social distancing and maintaining a distance of at least six feet from each other are now continuously being recommended by the health regulatory authorities around the world. ${ }^{11,25}$ In the era of social distancing, it is also true that most dental offices are not particularly spacious, with limited capacity to accommodate dental patients in the waiting areas; therefore, it is essential that the patients be scheduled in such a way that crowding is prevented, and the minimal required distance between individuals can be maintained. ${ }^{17} \mathrm{~A}$ large number of dental patients surveyed in this study showed their concern regarding the possibility that patients may be scheduled in a manner that they would be exposed to crowding and hence affirmed that they would like to inquire from their dental health care provider regarding this before visiting the dental office. Current guidelines also recommend limiting the number of patients to be seen by the dentist, prioritizing patients presenting with dental emergencies including pain, bleeding, swelling, and trauma. This would also reduce the number of patients that need an appointment with the dentist.

As dental health care providers, it is essential that the fear of patients regarding getting infected with COVID-19 from dental treatment be alleviated by ensuring that proper screening recommendations, social distancing, and other cross-infection control measures are rigorously followed in dental practices. This will guarantee that patients who require any dental treatment, which in the current scenario would majorly comprise dental emergencies, should not hesitate to seek proper management. However, it is the dental practitioner's responsibility 
to make sure that the current recommendations of the health regulatory authorities be followed in practice, while keeping updated of any changes or modifications that occur in the current guidelines as the situation emerges, to continue providing quality and safe dental services to the patients.

\section{Conclusion}

The knowledge and attitude of dental patients as assessed in this study indicate adequate understanding regarding the infection potential of the coronavirus and the importance of practicing cross-infection control measures in dental practices. However, the dental health professionals should take additional measures to educate dental patients on mechanism of potential spread of COVID-19 through the aerosols and droplets generated during dental procedures. They should also encourage the dental patients to be vigilant and question the cross-infection control measures practiced by the dentist to whom they go for dental treatment, to decrease their chances of acquiring an infection during their visit to the dental office.

\section{Funding}

None.

\section{Conflict of Interest}

None declared.

\section{Acknowledgment}

We would like to thanks Altamash Institute of Dental Medicine for their support.

\section{References}

1 Taha F, Joseph J, Janakiram C, Puttaiah R. Dental infection control practices and public perception: a cross-sectional study. J Int Oral Health 2015;7(12):20-26

2 CDC. Summary of Infection Prevention Practices in Dental Settings: Basic Expectations for Safe Care. Atlanta, GA: Centers for Disease Control and Prevention, US Dept of Health and Human Services; October 2016. https://www.cdc.gov/oralhealth/infectioncontrol/pdf/safe-care2.pdf. Accessed Oct 19, 2020

3 Minimum requirements for infection prevention and control. Geneva: World Health Organization; 2019. Available at: https:// www.who.int/infectionprevention/publications/min-req-IPCmanual/en/, Accessed October 19, 2020.

4 Setiawan AS, Zubaedah C. Application of health belief model on child's dental visit postponement during the COVID-19 pandemic. Eur J Dent 2020;14(suppl S1):S7-S13 doi:10.1055/ s-0040-1715784

5 Jayaweera M, Perera H, Gunawardana B, Manatunge J. Transmission of COVID-19 virus by droplets and aerosols: A critical review on the unresolved dichotomy. Environ Res 2020;188:109819. doi:10.1016/j.envres.2020.109819

6 Balogh EP, Miller BT, Ball JR, Committee on Diagnostic Error in Health Care; Board on Health Care Services; Institute of Medicine; Improving Diagnosis in Health Care. Washington (DC): National Academies Press (US); December 29, 2015.

7 Bizzoca ME, Campisi G, Muzio LL. Covid-19 pandemic: What changes for dentists and oral medicine experts? A narrative review and novel approaches to infection containment. Int J Environ Res Public Health 2020;17(11):3793 doi:10.3390/ ijerph17113793
8 Haleem A, Javaid M, Vaishya R. Effects of COVID-19 pandemic in daily life. Curr Med Res Pract 2020;10(2):78-79

9 Faccini M, Ferruzzi F, Mori AA, et al. Dental care during COVID-19 outbreak: A web-based survey. Eur J Dent 2020;14(suppl S1): S14-S19 doi:10.1055/s-0040-1715990

10 Ahmed MA, Jouhar R, Ahmed N, et al. Fear and practice modifications among dentists to combat Novel Coronavirus Disease (COVID-19) outbreak. Int J Environ Res Public Health 2020;17(8):2821

11 World Health Organization. Advice on the use of masks in the context of COVID-19: interim guidance, 5 June 2020. World Health Organization. Available at: https://apps.who.int/iris/ handle/10665/332293.

12 Ahmed N, Shakoor M, Vohra F, Abduljabbar T, Mariam Q, Rehman MA. Knowledge, Awareness and Practice of Health care Professionals amid SARS-CoV-2, Corona Virus Disease Outbreak. Pak J Med Sci 2020;36(COVID19-S4):S49-S56

13 Kamate SK, Sharma S, Thakar S, et al. Assessing knowledge, attitudes and practices of dental practitioners regarding the COVID-19 pandemic: a multinational study. Dent Med Probl 2020;57(1):11-17

14 Hussain I, Majeed A, Imran I, et al. Knowledge, Attitude, and Practices Toward COVID-19 in Primary Healthcare Providers: A Cross-Sectional Study from Three Tertiary Care Hospitals of Peshawar, Pakistan [published online ahead of print, 2020 Jul 6]. J Community Health 2020;1-9 doi:10.1007/ s10900-020-00879-9

15 Roy D, Tripathy S, Kar SK, Sharma N, Verma SK, Kaushal V. Study of knowledge, attitude, anxiety \& perceived mental healthcare need in Indian population during COVID-19 pandemic. Asian J Psychiatr 2020;51:102083

16 Khader Y, Al Nsour M, Al-Batayneh OB, et al. Dentists' awareness, perception, and attitude regarding COVID-19 and infection control: cross-sectional study among Jordanian dentists. JMIR Public Health Surveill 2020;6(2):e18798

17 Spagnuolo G, De Vito D, Rengo S, Tatullo M. COVID-19 Outbreak: An Overview on Dentistry. Int J Environ Res Public Health 2020;17(6):2094

18 Ahmed N, Maqsood A, Abduljabbar T, Vohra F. Tobacco Smoking a Potential Risk Factor in Transmission of COVID-19 Infection. Pak J Med Sci 2020;36(COVID19-S4):S104-S107

19 Yip HK, Tsang PC, Samaranayake LP, Li AH. Knowledge of and attitudes toward severe acute respiratory syndrome among a cohort of dental patients in Hong Kong following a major local outbreak. Community Dent Health 2007;24(1):43-48

20 Ashok N, Rodrigues JC, Azouni K, et al. Knowledge and apprehension of dental patients about MERS-A questionnaire survey. J Clin Diagn Res 2016;10(5):ZC58-ZC62

21 Ali S, Farooq I, Abdelsalam M, AlHumaid J. Current clinical dental practice guidelines and the financial impact of COVID-19 on dental care providers. Eur J Dent 2020;14(suppl S1): S140-S145 doi:10.1055/s-0040-1716307

22 Peng X, Xu X, Li Y, Cheng L, Zhou X, Ren B. Transmission routes of 2019-nCoV and controls in dental practice. Int J Oral Sci 2020;12(1):9

23 Sun J, Xu Y, Qu Q, Luo W. Knowledge of and attitudes toward COVID-19 among parents of child dental patients during the outbreak. Braz Oral Res 2020;34:e066

24 Ather A, Patel B, Ruparel NB, Diogenes A, Hargreaves KM. Coronavirus Disease 19 (COVID-19): Implications for Clinical Dental Care. J Endod 2020;46(5):584-595

25 Azim AA, Shabbir J, Khurshid Z, Zafar MS, Ghabbani HM, Dummer PMH. Clinical endodontic management during the COVID-19 pandemic: a literature review and clinical recommendations. Int Endod J 2020;53(11):1461-1471 doi:10.1111/ iej.13406 